\title{
COMPARATIVE STUDY OF WOOD FLOUR PHOTODEGRADATION OF TWO WOOD SPECIES SUBMITTED TO ARTIFICIAL WEATHERING
}

Matheus Poletto ${ }^{1, \wedge}$

\begin{abstract}
In this work Eucalyptus grandis and Dipteryx odorata were submitted to photodegradation by ultraviolet radiation. The effect of ultraviolet radiation irradiation on the color change and chemical composition of each wood flour were evaluated. The samples were submitted to a total of $500 \mathrm{~h}$ of artificial weathering using condensation stages and ultraviolet radiation B irradiation cycles. The changes in wood flour color were monitored by spectrocolorimetry, while the changes in wood chemical composition were evaluated by Fourier transform infrared spectroscopy. Both species showed changes in color with increased exposure time to artificial weathering. For both wood species the variation in color change was considered very appreciable after 500h. The Eucalyptus grandis specie showed appreciable color change after $120 \mathrm{~h}$, while for Dipteryx odorata specie the color change is appreciable only after $240 \mathrm{~h}$. The Fourier transform infrared spectroscopy results showed that lignin was strongly degrades by ultraviolet radiation radiation in both species. However, Dipteryx odorata was more resistant to photodegradation than Eucalyptus grandis, probably due to lower lignin content in this wood. The results clearly indicated that for the wood species studied the rate of weathering is influenced by wood species.
\end{abstract}

Keywords: Color change, FTIR, lignin, photodegradation, wood.

\section{INTRODUCTION}

Wood is commonly used in different applications such as building sector, furniture, composites and others industries for the production of structural and non-structural products (Cademartori et al. 2015, Yeniocak et al. 2015). However, when wood is exposed to outdoor applications, a complex combination of chemical and physical factors contributes to what is described as weathering (Pandey 2005, Chang et al. 2010), or in other words, the action of climatic agents on wood structure.

The weathering process is generally initiated by sunlight (UV irradiation) and its rate is enhanced by temperature, moisture, environmental pollutants and oxidative agents such as oxygen and/or ozone which are present in the outdoor environmental (Pandey 2005, Lesar et al. 2011). The rate of wood degradation in outdoor applications might also be affected by wood composition, as the presence of extractives and lignin, and wood specie (Cui et al. 2004, Pandey 2005, Lesar et al. 2011).

${ }^{1}$ Centro de Ciências Exatas, da Natureza e de Tecnologia (CENT), Universidade de Caxias do Sul (UCS), Bento Gonçalves, 
The interaction of photon energy from UV light with polymeric compounds distributed at the wood surfaces involves complex physical and chemical reactions (Pandey 2005). The degradation process initiates with the formation of free radicals by a combined action of UV irradiation and environmental conditions that attacks compounds in the extractives and depolymerise lignin and cellulose in the wood cell wall (Pandey 2005, Lesar et al. 2011). Wood contains several chromophoric functional groups associated with an aromatic skeleton, which makes wood susceptible to absorb light (Lesar et al. 2011). All wood chemical constituents can be affected by UV irradiation, however lignin is the most sensitive (Pandey 2005, Lesar et al. 2011). Among different wood components, lignin absorbs between $80 \%$ and $95 \%$ of the total UV irradiation due to its various reactive groups, such as hydroxyl groups, carboxyl groups, aromatic and phenolic groups and carbonyl groups (Lesar et al. 2011).

Weathering causes several changes in wood properties such as discoloration, loss of lightness, cracking, checking, roughening surface, among others (Cui et al. 2004, Cademartori et al. 2015). As a result, weathering reduces service life of wood and also increases maintenance cost (Lesar et al. 2011).

Several researchers have been investigated the weathering of wood using specimens from radial, longitudinal or tangential wood sections, wood plates, wood strips, among others (Hill et al. 2001, Pandey 2005, Chang et al. 2010, Cademartori et al. 2015). However, the literature lacks studies on the weathering of wood flour wastes, that after be generated by the lumber industries are normally stored in outdoor environments before use in other applications, such as reinforcement in composite materials. So, in this work, the artificial weathering of waste wood flour from Eucalyptus grandis and Dipteryx odorata was investigated using spectrocolorimetry and Fourier transform infrared spectroscopy (FTIR).

\section{MATERIALS AND METHODS}

\section{Materials}

The wood flour samples used in this study were obtained from wastes of the lumber industry in Brazil. The species investigated were Eucalyptus grandis (EUG) andDipteryxodorata (DIP), and Table 1 presents the chemical composition of the wood species studied that were obtained in a previous study (Poletto et al. 2012). Wood samples used in the artificial weathering having particle size between $2,4 \mathrm{~mm}$ and $0,7 \mathrm{~mm}$.

Table 1. Chemical composition of the wood species investigated.

\begin{tabular}{|l|c|c|c|c|}
\hline Wood species & $\begin{array}{c}\text { Holocellulose } \\
\mathbf{( \% )}\end{array}$ & $\begin{array}{c}\text { Lignin } \\
\mathbf{( \% )}\end{array}$ & $\begin{array}{c}\text { Extractives } \\
\mathbf{( \% )}\end{array}$ & $\begin{array}{c}\text { Ash } \\
\mathbf{( \% )}\end{array}$ \\
\hline Eucalyptus grandis (EUG) & $62,7 \pm 1,4$ & $32,1 \pm 1,0$ & $4,1 \pm 0,2$ & $1,1 \pm 0,3$ \\
\hline Dipteryx odorata (DIP) & $57,1 \pm 0,6$ & $30,4 \pm 0,4$ & $11,1 \pm 0,1$ & $1,5 \pm 0,2$ \\
\hline
\end{tabular}

\section{Artificial weathering}

Artificial weathering experiment was performed in a C-UV weathering device (Comexim Ltda, Brazil) equipped with eight UVB-313 lamps according to ASTM G154-06. Specimens were exposure to cycles of $4 \mathrm{~h}$ UV-light irradiation at $60^{\circ} \mathrm{C}$ followed by condensation for $4 \mathrm{~h}$ at $50^{\circ} \mathrm{C}$. The average irradiation was $0,71 \mathrm{~W} / \mathrm{m}^{2}$ at maximum intensity of $310 \mathrm{~nm}$ wavelengths. The wood samples were characterized at 120, 240 and $500 \mathrm{~h}$ after exposed to artificial weathering.

\section{Color test}

The color parameters $a^{*}, b^{*}$, and $L^{*}$ were determined by the CIELAB method. The $L^{*}$ represents the lightness, whereas $a^{*}$ and $b^{*}$ are the chromaticity coordinates. The $+a^{*}$ and $-a^{*}$ parameters represent red and green, respectively. The $+b^{*}$ and $-b^{*}$ parameters represent yellow and blue, respectively. $L^{*}$ can vary from 100 (white) to 0 (black) (Baysal et al. 2014). The color of the samples 
was measured by a color meter (CM-2500d Konica Minolta spectrophotometer) before and after artificial weathering. The color change $\left(\Delta E^{*}\right)$ was determined for each wood specie as follows:

$$
\begin{aligned}
& \Delta a^{*}=a_{f}^{*}-a_{i}^{*} \\
& \Delta b^{*}=b_{f}^{*}-b_{i}^{*} \\
& \Delta L^{*}=L_{f}^{*}-L_{i}^{*} \\
& \Delta E^{*}=\left(\Delta a^{* 2}+\Delta b^{* 2}+\Delta L^{* 2}\right)^{1 / 2}
\end{aligned}
$$

where $\Delta a^{*}, \Delta b^{*}$, and $\Delta L^{*}$ are the changes between the initial and final interval values.

\section{Fourier Transform Infrared (FTIR) Spectroscopy}

FTIR spectra were obtained by means of a Nicolet IS10-Thermo Scientific spectrometer. Wood powder sample of each specie $(5 \mathrm{mg})$ was dispersed in a matrix of $\mathrm{KBr}(100 \mathrm{mg})$, followed by compression to form pellets. The sample collection was obtained using 32 scans, in the range of 4000 $\mathrm{cm}^{-1}$ to $400 \mathrm{~cm}^{-1}$, at a resolution of $4 \mathrm{~cm}^{-1}$.

\section{RESULTS AND DISCUSSIONS}

\section{Color change}

The values of $\Delta L^{*}, \Delta a^{*}, \Delta b^{*}$ parameters of wood species studied after 120,240 and $500 \mathrm{~h}$ of artificial weathering are presented in Table 2 . The decrease in $\Delta L^{*}$ values for both wood species studied indicates that the specimens become darker after artificial weathering. However, this darkening was more pronounced in EUG than in DIP. The accentuated darkening in EUG is probably associated with the photodegradation of lignin and other non-cellulosic polysaccharides (Baysal et al. 2014) since EUG as a higher quantity of lignin than DIP, as can be seen in Table 1.

Table 2. Parameters after artificial weathering $\left(\Delta L^{*}, \Delta a^{*}, \Delta b^{*}\right)$.

\begin{tabular}{|c|c|ccc|}
\hline Wood specie & \multirow{2}{*}{ Parameter } & \multicolumn{3}{|c|}{ Time $(\mathrm{h})$} \\
\cline { 3 - 5 } & & 120 & 240 & 500 \\
\hline EUG & $\Delta \mathrm{L}^{*}$ & $-12,00 \pm 0,71$ & $-16,48 \pm 0,34$ & $-14,69 \pm 0,40$ \\
DIP & & $-1,93 \pm 1,17$ & $-6,61 \pm 0,33$ & $-7,34 \pm 0,79$ \\
\hline EUG & $\Delta \mathrm{a}^{*}$ & $0,0,24 \pm 0,15$ & $-4,42 \pm 0,40$ & $-3,64 \pm 0,27$ \\
\hline DIP & & $0,08 \pm 0,16$ & $-0,24 \pm 0,41$ & $-0,59 \pm 0,46$ \\
\hline EUG & $\Delta \mathrm{b}^{*}$ & $0,94 \pm 0,46$ & $-6,60 \pm 0,64$ & $-4,37 \pm 0,41$ \\
\hline DIP & & $--0,34 \pm 0,58$ & $-2,28 \pm 1,05$ & $-1,83 \pm 0,43$ \\
\hline
\end{tabular}

The positive values of $\Delta a^{*}$ after $120 \mathrm{~h}$ of irradiation indicate a tendency of both wood surfaces to become reddish. But when the exposure time increases the values of $\Delta a^{*}$ becomes negative, which is associated with a tendency of both wood surfaces to become greenish. The color change process is mainly associated with the formation of chromophoric groups as carbonyl and carboxyl groups resulting from degradation of lignin (Yeniocak et al. 2015). 
As can be seen in Table 2, EUG is more susceptible to become greenish than DIP. The extractive content in DIP is three times higher than in EUG, as presented in Table 1. It is possible that the higher quantity of extractives associated with lower quantities of lignin in DIP may protect wood from UV photodegradation. The photodegradation process in DIP may initiate in the extractives and as result the lignin photodegradation might occurs more slowly, reducing the rate of photodegradation. Chang et al. 2010 also observed that the rate of wood photodegradation was lessened by the presence of extractives in Cryptomeria japonica and Acacia confusa species. The negative values of $\Delta b^{*}$ indicate a tendency of both wood surfaces to become bluish when exposed to higher artificial weathering times. Once again the rate of photodegradation is higher in EUG than in DIP, which corroborates that extractives in DIP may act as a barrier retarding the lignin degradation in this wood specie.

The color change $\left(\Delta \mathrm{E}^{*}\right)$ considered not only the variations of color parameters, but also the differences in lightness, providing better interpretation of the photodegradation. Hikita et al. (2001) used the value of color change to define the levels of perceived difference in color, as presented in Table 3 .

Table 3. Classification of the color change ( $\left.\Delta \mathrm{E}^{*}\right)$ for woods.

\begin{tabular}{|c|c|}
\hline $\begin{array}{c}\text { Color change } \\
\left(\Delta \mathrm{E}^{*}\right)\end{array}$ & Classification \\
\hline $0-0,5$ & Negligible \\
$0,5-1,5$ & Slightly perceivable \\
\hline $1,5-3,0$ & Noticiable \\
$3,0-6,0$ & Appreciable \\
\hline $6,0-12$ & Very appreciable \\
\hline
\end{tabular}

The color change for wood species studied is shown in Figure 1. The color variation was sharper in the first evaluation times, mainly after $240 \mathrm{~h}$. After $500 \mathrm{~h}$ of UV irradiation, the changes in color for both wood species, $\Delta \mathrm{E}^{*}=15,75$ and $\Delta \mathrm{E}^{*}=7,61$ for EUG and DIP, respectively, can be classified as very appreciable. The EUG wood is more susceptible to color changes, while DIP is more resistant.

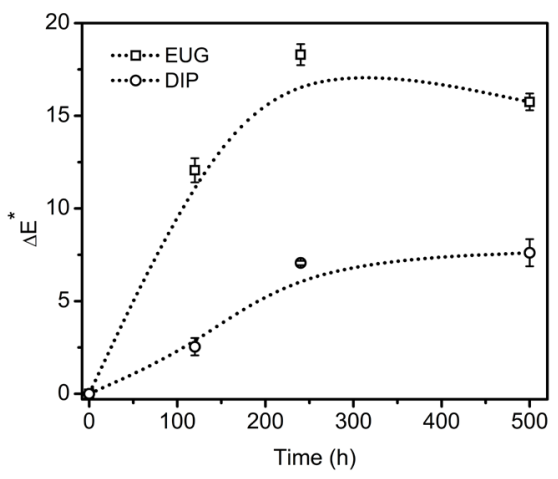

Figure 1. Color change $\left(\Delta \mathrm{E}^{*}\right)$ against time of artificial weathering for wood species studied.

As discussed before, the higher quantity of extractives in DIP may retard the photodegradation of lignin in this wood, which contribute to reduce the rate of photodegradation. Similar behaviour was observed by Barreto and Pastore (2009) for Mezilaurus itauba, a tropical wood that contained approximately 7\% of extractives. Chang et al. 2010 also observed that extractives absorbed light and scavenged free radicals, consequently retarding lignin oxidation during wood photodegradation. On the other hand, EUG was higher quantity of lignin associated with lower quantities of extractives, which 
can cause a faster photodegradation process involving the degradation of $\alpha$-carbonyl, biphenyl and ring-conjugated double bonds structures in lignin (Yeniocak et al. 2015).

\section{FTIR results}

The color change is a sensitive indicator of photodegradation of wood but it does not provide information about the chemical changes occurring in the wood structure (Tolvaj et al. 2011). So, the FTIR spectroscopy can be used to provide information about the changes in wood chemical structure after artificial weathering. FTIR spectra of EUG and DIP after $120 \mathrm{~h}$ and $500 \mathrm{~h}$ of artificial weathering are shown in Figure 2.
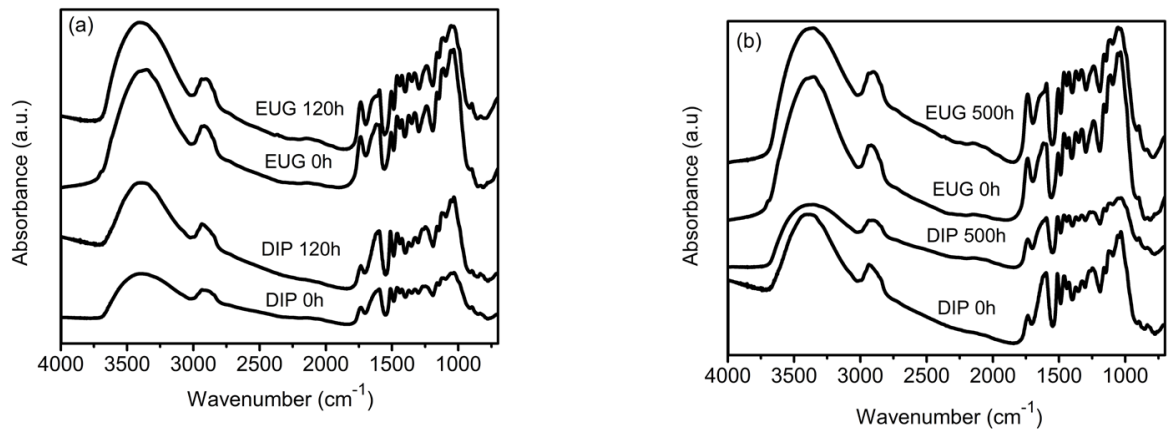

Figure 2. FTIR spectra of both wood species exposed to artificial weathering

(a) after $120 \mathrm{~h}$ and (b) $500 \mathrm{~h}$.

The FTIR spectrum from EUG and DIP after artificial weathering shows the same basic structure observed before exposure to UV-light irradiation. Because of their complexity, the spectra were evaluated into two regions, namely: the $\mathrm{OH}$ and $\mathrm{CH}$ stretching vibrations in the $3800-2700 \mathrm{~cm}^{-1}$ region and the fingerprint region which is assigned to stretching vibrations of different groups of wood components at $1800-800 \mathrm{~cm}^{-1}$. A strong broad band assigned to O-H stretching at $3000-3600 \mathrm{~cm}^{-1}$ and a band at $2800-3000 \mathrm{~cm}^{-1}$ related to asymmetric and symmetric methyl and methylene stretching groups present in the spectra of all of the wood components but most notably in the spectra for cellulose can be seen in the $\mathrm{OH}$ and $\mathrm{CH}$ stretching region.

In the fingerprint region the band at $1730 \mathrm{~cm}^{-1}$ is assigned to non-conjugated carbonyl group in hemicellulose and the band at $1510 \mathrm{~cm}^{-1}$ have their origin in the aromatic ring of lignin. The bands at 1375,1160 and $898 \mathrm{~cm}^{-1}$ are mainly due to carbohydrates, while the band at 1462 and $1422 \mathrm{~cm}^{-1}$ also have significant contribution from lignin (Pandey and Vuorinen 2008, Poletto et al. 2012).

The intensity of absorption band at around 1510, 1462 and $1422 \mathrm{~cm}^{-1}$ decreased after artificial weathering. This is also accompanied by a successive increase in the intensity of the band at 1730 $\mathrm{cm}^{-1}$. Most significant changes can be seen in the intensity of aromatic lignin $\mathrm{C}=\mathrm{C}$ band at $1510 \mathrm{~cm}$ ${ }^{1}$. The reduction in the intensity of $\mathrm{C}=\mathrm{C}$ at $1510 \mathrm{~cm}^{-1}$ band for $\mathrm{EUG}$, even at $120 \mathrm{~h}$, indicates the fast degradation of lignin in this wood. This is accompanied by the increased of the carbonyl band at $1730 \mathrm{~cm}^{-1}$, which indicates the photo-oxidation of both wood surfaces (Pandey 2005, Mitsui and Tsuchikawa 2005). The intensities of peaks associated with carbohydrates at 1375,1160 and $898 \mathrm{~cm}^{-1}$ are not significantly affected by irradiation, even at $500 \mathrm{~h}$. 
In order to evaluated the rate of lignin decay and carbonyl formation with the artificial weathering, the intensities of the carbonyl band at $1730 \mathrm{~cm}^{-1}$, lignin reference band at $1510 \mathrm{~cm}^{-1}$ and a carbohydrate reference band at $898 \mathrm{~cm}^{-1}$ were measured according to a previous work (Poletto et al. 2012). The relative changes in the lignin carbohydrate ratio and carbonyl carbohydrate ratio at different exposure times were calculated from the ratio of the band area of the peaks at $1510 \mathrm{~cm}^{-1}$ and $1730 \mathrm{~cm}^{-1}$, respectively, in relation to band area of the peak at $898 \mathrm{~cm}^{-1}$. The relative changes in the lignin/carbohydrate ratio $\left(\mathrm{A}_{1510} / \mathrm{A}_{898}\right)$ and carbonyl carbohydrate ratio $\left(\mathrm{A}_{1730} / \mathrm{A}_{898}\right)$ at different exposure times are shown in Figure 3 and Figure 4, for EUG and DIP, respectively.

The lignin/carbohydrate ratio decreases for both wood species studied with the increasing in irradiation time. The decay in lignin is more pronounced for EUG, which corroborates the results from color change. After 500h exposed to artificial weathering the lignin decay in EUG continues to decline, as can be seen in Figure 3, while for DIP, there is a tendency to stabilize the lignin decay, as presented in Figure 4. On the other hand, the carbonyl carbohydrate ratio increases for both wood species studied with the increasing in irradiation time. This behavior is observed due the liberation of $\mathrm{C}=\mathrm{O}$ groups due to photodegradation of lignin and some compounds from extractives. The FTIR results are in agreement with the color change results and also indicate that DIP is more resistant to photodegradation than EUG.

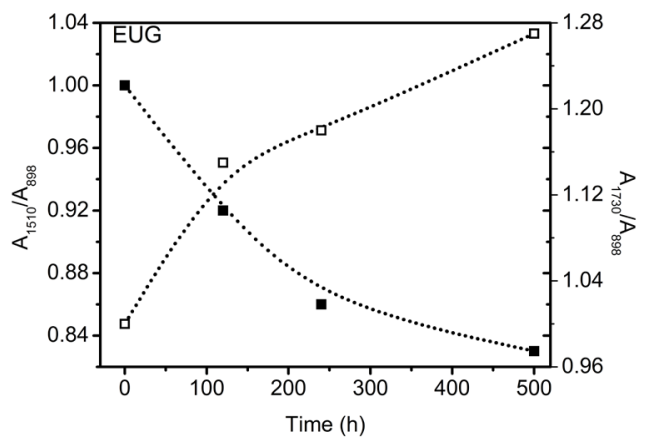

Figure 3. Lignin decay ( $\bullet$ ) and formation of carbonyl groups ( $\square)$ for EUG.

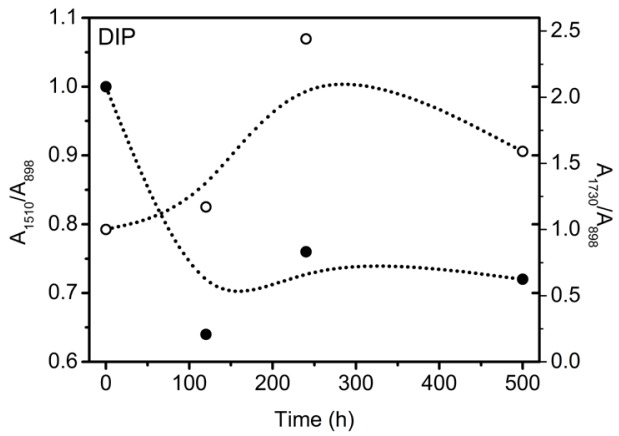

Figure 4. Lignin decay $(\bullet)$ and formation of carbonyl groups ( $($ ) for DIP. 


\section{CONCLUSIONS}

The wood species studied showed discoloration and formation of carbonyl groups caused by UV photodegradation. After $500 \mathrm{~h}$ exposed to artificial weathering the photodegradation for both species can be classified as very appreciable. The EUG specie presents the greater photodegradation, while DIP was less susceptible. This behavior may be associated with the higher rate of lignin photodegradation in EUG than in DIP. The results also indicated that lignin can promote a higher rate of wood photodegradation and the generation of carbonyl groups was very high even for shorter periods of exposure. In addition, the chemical composition of wood directly influences on the photodegradation process. Finally, the results suggest that the DIP has a higher resistance to artificial weathering than EUG, and is most suitable for outdoor applications.

\section{ACKNOWLEDGEMENTS}

The author thanks Prof. Ricardo Campomanes Santana for supplying the Dipteryx odorata sample used in this study.

\section{REFERENCES}

Barreto, C.C.K.; Pastore, T.C.M. 2009. Resistance to artificial weathering of four tropical woods: the effect of the extractives . Ciência Florestal 19(1):23-30.

Baysal, E.; Degirmentepe, S.; Simsek, H. 2014. Some surface properties of thermally modified scots pine after artificial weathering. Maderas Ciencia y tecnología 16(3):355-364.

Cademartori, P.H.G.; Missio, A.L.; Mattos, B.D.; Gatto, D.A. 2015. Natural weathering performance of three fast-growing eucalypt woods. Maderas. Ciencia y tecnología 17(4):799-808.

Chang, T.C.; Chang, H.T.; Wu, C.L.; Chang, S.T. 2010. Influences of extractives on the photodegradation of wood. Polymer Degradation and Stability 95:516-521.

Cui, W.; Kamdem, D.P.; Rypstra, T. 2004. Diffuse reflectance infrared Fourier transform spectroscopy (DRIFT) and color changes of artificial weathering wood. Wood and Fiber Science 36(3):291-301.

Hikita, Y.; Toyada, T,; Azuma, M. 2001. Weathering testing timber - discoloration. In: Imamura, Y. High performance utilization of wood for outdoor uses. Press-net Kyoto, Japan.

Hill, C.A.S.; Cetin, N.S.; Quinney, R.F.; Derbyshire, H.; Ewen, R.J. 2001. An investigation of the potential for chemical modification and subsequent polymeric grafting as a mean of protecting wood against photodegradation. Polymer Degradation and Stability 72:133-139.

Lesar, B.; Pavlič, M.; Petrič, M. Škapin, A.S.; Humar, M. 2011. Wax treatment of wood slows photodegradation. Polymer Degradation and Stability 96:1271-1278.

Mitsui, K.; Tsuchikawa, S. 2005. Low atmospheric temperature dependence on photodegradation of wood. Journal of Photochemistry and Photobiology B: Biology 81: 84-88.

Pandey, K.K. 2005. Study of the effect of photo-irradiation on the surface chemistry of wood. Polymer Degradation and Stability 90:9-20. 
Pandey, K.K.; Vuorinen, T. 2008. Comparative study of photodegradation of wood by a UV laser and a xenon light source. Polymer Degradation and Stability 93:2138-2146.

Poletto, M.; Zattera, A.J.; Santana, R.M. 2012. Structural differences between wood species: evidence from chemical composition, FTIR spectroscopy, and thermogravimetric analysis. Journal of Applied Polymer Science 126:E336-E343.

Tolvaj, L.; Persze, L.; Albert, L. 2011. Thermal degradation of wood during photodegradation. Journal of Photochemistry and Photobioly B: Biology 105:90-93.

Yeniocak, M.; Goktas, O.; Colak, M.; Ozen, E.; Ugurlu, M. 2015. Natural coloration of wood material by red beetroot (Beta vulgaris) and determination color stability under UV exposure. Maderas. Ciencia y tecnología 17(4):711-722. 